\title{
DISCUSSÕES EM TORNO DOS ARQUIVOS PESSOAIS FACE À TEORIA ARQUIVÍSTICA
}

\author{
RENATO DE MATTOS \\ ADRIANA ARROJADO CORREIA PEREIRA**
}

\begin{abstract}
RESUMO
Nas últimas décadas, os arquivos pessoais vêm assumindo um lugar de destaque no âmbito dos estudos arquivísticos. Com efeito, o crescente interesse que a temática desperta se fundamenta em suas especificidades teóricas e na potencialidade informacional que os seus acervos oferecem aos estudiosos de diversas áreas. Contudo, apesar de ocupar um importante espaço na Arquivologia, o tema dos arquivos pessoais ainda é objeto de controvérsias entre os pesquisadores da área. Com o objetivo de identificar parte das questões que os arquivos dessa natureza colocam à teoria arquivística, por meio da revisão da literatura, o artigo apresenta alguns dos olhares divergentes que hoje persistem sobre o estatuto arquivítico dos arquivos pessoais.
\end{abstract}

PALAVRAS-CHAVE: Arquivologia; Arquivos Pessoais; Teoria Arquivística.

DISCUSSIONS ABOUT PERSONAL ARCHIVES IN FRONT OF ARCHIVAL THEORY

\begin{abstract}
In the last decades, personal archive has been occupying a prominent place in archival studies. In fact, the growing interest in the theme is based on its theoretical specificities and on the informational potential that its collections offer to researchers from various areas. However, although it occupies an important space in the Archival Science, the theme still remains as an object of controversies in the field. In order to identify some of these controversies about the nature of personal archives we intend, through a review of the literature, to presents some of the divergent views that persist on the archival principles of personal archives today.
\end{abstract}

KEYWORDS: Archival Science; Personal Archives; Archival Theory.

*Professor Adjunto II do Departamento de Ciência da Informação do Instituto de Artes e Comunicação Social da Universidade Federal Fluminense (IACS/UFF). Professor do Programa de Pós-Graduação em Ciência da Informação da Universidade Federal Fluminense (PPGCI/UFF).

* Graduação (bacharel e licenciado) em História pela Universidade Federal Fluminense (2013). Possui graduação (bacharel) em Arquivologia pela Universidade Federal Fluminense (2017). Mestranda do Programa de Pós-Graduação em Ciência da Informação da Universidade Federal Fluminense (PPGCI/UFF) - Niterói - RJ (Brasil). 


\section{APRESENTAÇÃO}

Nas últimas décadas, com cada vez mais frequência, os arquivos pessoais passaram a ocupar um importante espaço dentre os estudos empreendidos na área da Arquivologia. Ao longo desse período, tanto no Brasil quanto no exterior, se verificou a profusão de publicações e eventos acadêmicos dedicadas à discussão das especificidades características dos arquivos produzidos e acumulados por pessoas físicas. Paralelamente, também se observou o surgimento e a consolidação de importantes instituições hoje consideradas referências na custódia de arquivos pessoais e na elaboração de metodologias específicas para o tratamento de documentos dessa natureza, dentre as quais, podemos assinalar a Casa de Oswaldo Cruz (COC/Fiocruz), o Centro de Pesquisa e Documentação de História Contemporânea do Brasil (CPDOC) da Fundação Getulio Vargas (FGV) e Fundação Fernando Henrique Cardoso (FFHC).

Representando uma valiosa fonte da experiência humana em seus múltiplos matizes, os arquivos pessoais constituem um campo fértil de estudos, tanto como instrumento quanto como objeto em si, e, nos últimos anos, vêm sendo explorados por diversas disciplinas. Não obstante, em que pese o crescente interesse pelos arquivos pessoais, o reconhecimento de seu estatuto arquivístico ainda hoje é colocado em xeque por alguns pesquisadores da área. Dentre as principais alegações contrárias à compreensão dos arquivos pessoais enquanto arquivos, dinstinguem-se aquelas assentadas na premissa de que, por seu caráter informal e discricionário, os documentos produzidos e acumulados por um indíviduo são desprovidos de valor probatório. Como consequência, de acordo com a perspectiva de autores que são referências no estudo destes documentos, o resultado mais alarmante deste quadro é o tratamento de tais conjuntos documentais segundo abordagens alheias à teoria arquivística.

Assim, por meio da revisão da literatura, o presente artigo visa identificar algumas questões que os arquivos pessoais colocam à teoria arquivística e que contribuem para sua marginalização no universo da disciplina. Para tal, deve-se, ainda que em linhas gerais, mapear o lugar destes arquivos no desenvolvimento da Arquivologia. Em seguida, foram analisados pontos que fragilizam os arquivos pessoais, destacando vozes que relutam em reconhecêlos como arquivos. Por último, a fim de destacar a importância do emprego da metodologia arquivística, será apresentada a 
perspectiva que defende o reconhecimento do estatuto arquivístico desses conjuntos e o seu tratamento em conformidade com a abordagem contextual.

\section{O LUGAR DOS ARQUIVOS PESSOAIS NA CONSOLIDAÇÃO DA ARQUIVOLOGIA}

Compreender o lugar que a temática dos arquivos pessoais ocupou no âmbito dos estudos arquivísticos empreendidos até as décadas finais do século passado exige um breve exame do espaço em que a Arquivologia se desenvolveu e constituiu enquanto ciência: os arquivos públicos. Como a experiência profissional de parte expressiva dos principais teóricos da área foi assentada em instituições arquivística públicas, suas reflexões estiveram presas, em grande medida, ao lastro desta realidade específica e, portanto, estiveram voltadas prioritariamente aos documentos produzidos em ambientes públicos e institucionais. Nessa perspectiva, conforme assinala Velloso (2012), para muitos estudiosos da área, apenas os documentos produzidos em meio coorporativo eram considerados como típicos de arquivo.

De acordo com Abreu (2016), as análises apresentadas em 1898 por Muller, Feith e Fruin no clássico Manual de Arranjo e Descrição de Arquivos restringiram a natureza do arquivo aos documentos de caráter oficial recebidos ou produzidos por órgãos públicos, não abarcando, desta forma, a produção e/ou acumulação de conjuntos documentais referentes a pessoas físicas. Anos mais tarde, Hilary Jenkinson ampliou os estudos sobre os arquivos, compreendendo que, além da natureza administrativa, o conceito de documento de arquivo abrangeria também aqueles produzidos no âmbito privado. Segundo Abreu (2016), é possível apreender uma dimensão pessoal na concepção jenkinsoniana de arquivos, uma vez que o teórico afirmava que o documento arquivístico "deve ser preservado como fonte de informação pela pessoa ou pessoas responsáveis pela transação e/ou sucessores." (JENKINSON apud ABREU, 2016).

Por sua vez, foi Casanova (1928) que, além de incluir os arquivos de natureza pública e privada, incorporou em sua teorização os arquivos produzidos por pessoas, independentemente de sua carreira, formação ou lugar de produção. O autor reconheceu o caráter orgânico de tais registros e relacionou sua preservação à memória da finalidade pela qual os documentos foram gerados. Assim como Casanova, Brenneke (1953) contemplou em sua 
conceituação os documentos produzidos por pessoas físicas, ainda que restringisse essa produção às atividades legais e/ou profissionais. (ABREU, 2016, p.30).

Nos anos seguintes à Segunda Guerra Mundial, período marcado pelo aumento do volume documental resultado do desenvolvimento tecnológico, administrativo e burocrático, a perspectiva da gestão documental emergiu (SCHMIDT apud ABREU, 2016, p. 30), reforçando ainda mais o lugar secundário da temática dos arquivos pessoais dentro da teoria arquivística (YEO apud ABREU, 2016, p. 31). Por seu turno, na década de 1950, Schellenberg abriria espaço em direção ao reconhecimento dos documentos produzidos por pessoas enquanto arquivos, posto que estes, em seu entendimento, podiam ser produzidos por toda entidade pública ou privada. Os arquivos pessoais, segundo o autor, estariam implicitamente incluídos nessa última categoria jurídica, desde que fossem expedidos ou recebidos no exercício de encargos legais. Para Schellenberg, a preservação destes registros se justificava por consistirem em provas das funções, decisões, métodos, operações ou outras atividades da instituição geradora, além do valor informativo que carregavam. (ABREU, 2016, p. 31).

Marginalizados dentro do quadro teórico da literatura arquivística, os arquivos pessoais foram, ao longo desse período, custodiados por bibliotecas e museus, denominados genericamente como "coleções", "manuscritos" ou "papéis pessoais." (OLIVEIRA, 2012). Foi principalmente a partir do movimento de renovação historiográfica observado a partir da década de 1960 que estes arquivos ganharam visibilidade. Conforme esclarece Lopez (1996, p. 16), nesse período despontou nos estudos históricos uma tendência transformadora voltada à ampliação do conceito de fonte histórica. Repercutindo em outras áreas das Ciências Humanas, como Antropologia, a Ciência Política, a Sociologia e a Psicologia, este movimento de renovação contribuiu para que os arquivos pessoais fossem alçados ao status de um importante manancial de informações, ampliando significativamente entre os profissionais de arquivo a preocupação com seu tratamento e salvaguarda. (LOPEZ, 1996).

No contexto arquivístico brasileiro, a chamada Lei de Arquivos (Lei 8.159 de 1991) representou um importante avanço no sentido da proteção dos arquivos pessoais ao incluir os conjuntos de documentos produzidos e recebidos por pessoas físicas na definição de arquivo expressa em seu segundo artigo. De fato, o estatuto arquivístico dos arquivos pessoais foi reforçado ainda mais no décimo primeiro artigo, o qual é taxativo em definir os arquivos 
privados enquanto conjuntos documentais produzidos ou recebidos por pessoas físicas ou jurídicas, em decorrência de suas atividades. (BRASIL, 1991).

Já em seu décimo segundo artigo, a Lei de Arquivos estabelece que, quando considerados fontes relevantes para a história e o desenvolvimento científico nacional, esses arquivos podem ser identificados pelo Poder Público como de interesse público e social. (BRASIL, 1991). Com efeito, tal reconhecimento foi regulamentado posteriormente a partir da publicação em 2002 do Decreto 4.073. De acordo com este dispositivo:

Art. 26. Os proprietários ou detentores de arquivos privados declarados de interesse público e social devem manter preservados os acervos sob sua custódia, ficando sujeito à responsabilidade penal, civil e administrativa, na forma da legislação em vigor, aquele que desfigurar ou destruir documentos de valor permanente. (BRASIL, 2002).

As passagens acima não apenas demonstram a existência de um aparato legal que assegura o estatuto de arquivo aos conjuntos documentais produzidos ou recebidos por pessoas físicas no desempenho de suas atividades, como também regulamentam questões a eles atinentes. Elas admitem a possibilidade da declaração desses registros como de interesse público e social quando estes apresentam um aspecto que é característico dos arquivos permanentes (cujo valor secundário justifica sua conservação): seu uso científico, cultural, social e histórico. Tal assunção instituiu a necessidade de preservação dos arquivos privados de interesse público e social, apontando seus responsáveis legais e os sujeitando a sanções nas esferas penal, civil e administrativa caso desfigurem ou destruam documentos de caráter permanente.

Não obstante este esforço legal e a já referida valorização pela qual passaram nas últimas décadas do século $X X$, ainda que tímida e muito tributária das mudanças teórica-metodológicas gestadas entre os historiadores a partir da década de 1960, os arquivos pessoais ainda hoje ocupam um lugar secundário na literatura arquivística. Ademais, observa-se na comunidade acadêmica uma resistência em reconhecer os arquivos pessoais como arquivos. É possível conjecturar que tal posição derive não apenas da falta de tradição em experiências práticas e em reflexões teóricas sobre estes conjuntos documentais, mas também das complexas questões que os arquivos pessoais suscitam. O resultado mais alarmante desta marginalização, sob o ponto de 
vista da Arquivologia, é o tratamento destes conjuntos documentais segundo abordagens alheias à teoria arquivística.

\section{OLHARES DIVERGENTES SOBRE OS ARQUIVOS PESSOAIS}

Calleja (2007) é uma das vozes que relutam em reconhecer os conjuntos documentais produzidos por pessoas como arquivos. Para justificar sua posição, a arquivista uruguaia elenca uma série de argumentos: estes documentos não possuíram funções específicas estabelecidas por lei, não possuem um quadro de classificação científico - ainda que o produtor ou um arquivista construam um quadro, este seria desprovido de rigor científico e carregado de subjetividade -, carecem de organicidade científica, apresentariam apenas a terceira fase do ciclo de vida e, por fim, não estariam sujeitos a uma avaliação criteriosa, uma vez que, comumente, os arquivos pessoais são entregues às instituições custodiaras após terem após por um processo de seleção arbitrário promovido por seus responsáveis legais. (CALLEJA, 2007 p. 3).

Ademais, a autora manifesta sua inquietação terminológica e indaga seus pares a respeito da denominação mais adequada para estes tipos de documentos. Deviam ser referidos como "arquivos pessoais" mesmo que supostamente lhes faltem as condições necessárias aos arquivos, como a organicidade, o ciclo de vida e a avaliação? A partir dessas indagações, Calleja (2007, p. 4) traz novamente à baila o seguinte problema: os documentos produzidos por pessoas devem ser tratados como arquivos ou coleções? O encaminhamento dessa questão acarreta desdobramentos importantes. Dela deriva a determinação do campo do conhecimento a que cabe o tratamento destes conjuntos, gerando, assim, implicações metodológicas. Isto significa, em última instância, retornar a um ponto que, ao menos de acordo com as definições da maioria dos teóricos da área e que estão expressas em leis e normas internacionais, já foi superado.

A imparcialidade, atributo fundamental atribuído ao documento arquivístico, é mais um aspecto que gera divergências entre os acadêmicos. De acordo com Duranti (1994), os documentos de arquivo são inerentemente verdadeiros, pois as razões pelas quais são produzidos e as rotinas processuais implicadas em sua criação garantem que não há intenções outras neste processo além do cumprimento de atividades, caracterizando a imparcialidade de sua produção. Diversos autores, muitos dos quais se consideram alinhados ao pensamento pós-moderno, teceram 
severas críticas a essa característica, geralmente associando-a a um ideal "cientificista" e a uma crença quase ingênua na objetividade, que seriam típicas de uma visão "positivista".

Se a ideia de imparcialidade já é polêmica quando pensada nos arquivos institucionais, o é ainda mais no caso dos pessoais. Primeiramente, a noção de circunstâncias ou rotinas processuais de criação é problemática para os arquivos de pessoas, visto que tais conjuntos abrigam uma grande quantidade de documentos discricionários e informais e seu produtor, na maioria das vezes, já faleceu, não podendo revelar informações importantes para a compreensão dessas rotinas (ainda que outras metodologias de pesquisa permitam uma aproximação dessas informações). Em segundo lugar, e especialmente, a concepção de que o motivo de produção e de guarda do documento reside em cumprir e provar atividades é bastante questionável para muitos teóricos ${ }^{1}$. Na vida de uma pessoa, arquivar significa única e objetivamente provar atividades? Estaria a ideia de imparcialidade mascarando uma vasta gama de razões outras (bem mais subjetivas) envolvidas tanto na produção quanto na preservação de documentos (mesmo que não consciente e deliberadamente)? Nesse sentido, a imparcialidade deságua em outra questão: os sentidos envolvidos no arquivar.

Ao explorar a prática do "autoarquivamento" comum entre titulares de arquivos pessoais, McKemmish (2013) afirma que a funcionalidade destes conjuntos documentais está em sua capacidade de provar, testemunhar uma vida. No nível pessoal, guardar registros é uma forma de testemunhar e memorializar nossas vidas - nossa existência, experiências, atividades, inter-relacionamentos, identidade, enfim, nosso lugar no mundo.

Entendendo que essa prática corresponde a um impulso humano fundamental de dar testemunho, um ato instintivo de fazer o próprio relato, McKemmish (2013) recorre ao instrumental metodológico da Sociologia para identificar as forças sociais promotoras dos registros

\footnotetext{
${ }^{1}$ Catherine Hobbs, Maryanne Dever e Verne Harris questionam a certeza em relação ao valor probatório no arquivo pessoal. Entendendo como redutora a relação entre documento e prova, os autores apostam em um enfoque sobre aquilo que não é admitido pelo ponto de vista probatório, como o comportamento anômalo na organização de documentos pessoais e a presença do "selvagem" neste tipo de arquivo. Segundo Hobbs, a palavra "prova" opera no sentido de levar o documento pessoal para o universo do factual e do jurídico, lançando-o na direção da responsabilidade pública. No caso dos arquivos pessoais, porém, estão envolvidos outros elementos que transcendem a ideia de transação de atividades (sejam essas atividades oficiais, pessoais, comerciais ou formais), fazendo destes conjuntos documentais um espaço de múltiplos construtos (Hobbs, 2016).
} 
pessoais. Em sua leitura, a ação de manter registros é um sistema social institucionalizado que, no caso de arquivos de pessoas, relaciona-se à construção da identidade e da memória individual e coletiva (provas de si, provas de nós), a um vetor autobiográfico (produção da narrativa de si) e à necessidade de um indivíduo deixar rastros que garantam seu lugar no presente e no futuro.

Por sua vez, ao discutir o processo pessoal de arquivamento, Artières (1998) afirma que o ato de arquivar a própria vida é uma prática cotidiana comum, na qual os indivíduos, orientados por intenções sucessivas e às vezes contraditórias, procedem a uma triagem de seus papéis: preservam alguns, descartam outros e os arrumam e rearrumam continuamente. Isto é, o arquivamento do "eu" corresponderia a um exercício plural e incessante, pois até o último instante os arquivos são modificados, refeitos. Mediante essas práticas minúsculas, nos colocamos frente a um espelho, confrontamos nossa imagem social com nossa imagem íntima e construímos uma imagem para nós mesmos e, às vezes, para os outros. Todavia, ressalva ele, não arquivamos nossas vidas propriamente ditas, mas sim "fazemos um acordo com a realidade, manipulamos a existência: omitimos, rasuramos, riscamos, sublinhamos, damos destaque para certas passagens." (ARTIĖRES, 1998, p. 11).

Artières (1998) identifica ainda como traços comuns a tal prática os desejos de tomar distância de si mesmo (neutralizando-se) e de testemunhar a própria vida, ambos como parte de um movimento no qual o produtor do arquivo se coloca em uma espécie de diálogo com um potencial interlocutor. Segundo o autor, a constituição de um arquivo pessoal se dá em função de um futuro leitor (autorizado ou não), seja este leitor o próprio titular, seus familiares, seus amigos. Assim, embora o arquivamento do "eu" seja uma ação íntima, muitas vezes ela atende a uma função pública, porque arquivar a própria vida representa uma forma de publicá-la e tentar fazer com que ela perdure no tempo (mesmo após a morte). Nesse sentido, constituir um arquivo pessoal corresponderia a um exercício de testemunhar a própria vida e escrevê-la do modo como o produtor do arquivo a enxerga ou como gostaria que os outros a enxergassem. Seria, portanto, a construção de uma narrativa, de uma imagem para si e para seu possível público, defendendo-se previamente de possíveis leituras posteriores.

Testemunhar a própria vida. Fabricar uma memória individual e coletiva. Produzir uma narrativa de si. Construir uma imagem para si e para os outros. Realizar um gesto puro de entesouramento. Eternizar-se. As reflexões trazidas pelos autores 
acima permitem pensar que há uma multiplicidade de sentidos envolvidos na formação de um arquivo pessoal, processo no qual ocorrem seleções, destaques e omissões. Esses diversos sentidos e ações podem sugerir um alto teor de intencionalidade em que o arquivar estaria embebido; fato que possibilita, no mínimo, questionar e, no limite, negar a noção de imparcialidade. Outrossim, eles atingem outra propriedade dos documentos de arquivo: a naturalidade.

À luz daquelas leituras, em lugar de um fluxo contínuo e progressivo de acumulação, o arquivamento do "eu" pode ser entendido efetivamente como um movimento sucessivo, mas que se faz e refaz, em distintas temporalidades. De acordo com os propósitos do titular, a partir de lógicas e critérios que podem mudar no transcorrer do tempo, novos significados são atribuídos aos documentos, acarretando em reconfigurações dos materiais, bem como, em certas situações, no estabelecimento de novas relações entre eles - o que difere da ideia de uma "coesão espontânea" entre os documentos presente no conceito de naturalidade. Ademais, é comum o conjunto sofrer interferências de terceiros, principalmente quando a transferência do arquivo se dá sem o conhecimento ou a vontade manifesta do titular após sua morte. Tal circunstância contribuiria para se colocar ainda mais em dúvida a noção de naturalidade, que já seria discutível no âmbito da própria acumulação operada pelo titular, conforme mencionado acima.

Outro aspecto discutido pelas vozes divergentes são os agentes, para além de parentes e pessoas próximas ao produtor, que exercem influência sobre o arquivo pessoal. Segundo essas perspectivas, na prática de seu ofício, o arquivista promove intervenções no conjunto documental, opera seleções e "silenciamentos", imprimindo uma determinada ótica nos resultados de seu trabalho. Desse modo, ele também teria responsabilidade na produção dos registros que servem de fonte para quem se debruça sobre os arquivos. Apontando para a dimensão ativa da prática arquivística na conformação da memória social, Cook (2012) declara que os arquivistas dispõem de um enorme poder, uma vez que a mediação arquivística não é neutra nem são inócuos seus efeitos ${ }^{2}$

${ }^{2}$ De acordo com Anheim e Poncet, frente a um leque de possibilidades que a documentação oferece, a dimensão de escolha no tratamento arquivístico confere ao 
Para Heymann (1997), tanto o arquivista quanto o documentalista exercem um papel preponderante no processo de "produção" do arquivo pessoal enquanto fonte e, consequentemente, influenciam a construção da narrativa histórica. A ingerência destes profissionais, juntamente com a de parentes e secretários, compõe um plano de subjetividades intermediárias, situada entre a subjetividade que orientou a acumulação do titular e a do pesquisador, que se vale dos documentos do arquivo para formular o discurso histórico.

Seguindo a linha de raciocínio da autora (HEYMANN, 1997), a subjetividade do arquivista é encoberta pela pragmática necessária ao seu trabalho, a qual torna o conjunto documental acessível física e logicamente, mas, em contrapartida, promove exclusões. Neste sentido, este profissional produz o "resíduo" ou "lixo histórico", isto é, documentos desvalorizados por supostamente não responderem aos interesses de pesquisa e que ocupam um lugar secundário nas fases de arranjo e descrição. Assim, nestas etapas, de acordo com determinados aspectos que se opta por valorizar, alguns documentos são selecionados e desfrutam de um lugar privilegiado, ao passo que outros são relegados a classificações generalizantes (como "miscelânea", "diversos", "correspondência geral", etc.), que em geral estão condenadas à descrições sucintas e pouco minuciosas, não obstante o volume de documentos e a multiplicidade de informações que comportam. Desse modo, para Heymann (1997), o arquivista atua em um plano invisível de subjetividade e intervenção, posto que escamoteado pela pragmática de seu ofício e ofuscado tanto pela materialidade do arquivo quanto pela obra produzida a partir das fontes. Um plano silencioso, porém, não menos efetivo. (HEYMANN, 1997).

Tal qual o arquivista, consoante essa perspectiva, a instituição de custódia também exerceria influência na conformação dos documentos, corroborando a tese de que a guarda, bem como o tratamento documental, não é neutra. Um arquivo pessoal ingressa em uma instituição de guarda em caráter permanente respondendo a interesses de pesquisa, culturais e sociais, ou seja, seu valor secundário - e por meio de compra ou doação. Sua preservação se justifica pelo valor que lhe é atribuído; por essa razão, em geral são conservados arquivos de políticos, cientistas, artistas, isto é, pessoas com visibilidade na vida pública,

arquivista o papel não só de conservador, mas de produtor de saber (Anheim \& Poncet, 2004 apud Heymann, 2012). 
consideradas de grande relevância e capazes de ocupar um lugar no imaginário da sociedade. Destarte, tanto o gesto de um titular ou sua família doar ou vender um acervo como o de uma instituição barganhar sua aquisição indicam que àquele conjunto é conferida uma determinada importância e carregam consigo interesses e projetos - os quais deixarão suas marcas no tratamento documental.

De acordo com Lissovsky, Vianna e Sá (1986), o centro de documentação histórica detém um poder de monumentalizar um arquivo privado, dotando-o de uma dimensão histórica e pública. A doação de um arquivo a este tipo de instituição atenderia a um desejo de monumentalização e de imortalidade que pode partir do titular - dado que um dos sentidos que presidem a acumulação dos seus documentos é a lógica de edificação de uma imagem histórica, ainda que nem sempre essa lógica seja seguida pela instituição que os preservará. Conforme os autores pontuam:

A produção de uma imagem é fruto tanto do que se exibe quanto do que se esconde. Nesta operação participam tanto o círculo familiar do arquivador quanto as instituições de memória (...). É difícil imaginar o gesto de doação sem o espírito de notabilização. Do ponto de vista da memória, não se exibe o que não se revela; não se expõe conscientemente o que não seja rentabilizável como preservação de imagem. (LISSOVSKY et al., 1986, p. 69).

O sentido do arquivo dentro da instituição custodiadora, sob essa perspectiva, afetaria a forma como o conjunto documental será tratado: que representação será feita do conjunto, a partir de qual viés, com que finalidade, o que será priorizado e o que será omitido ou minimizado.

\section{ARQUIVOS PESSOAIS ENQUANTO ARQUIVOS: UMA ABORDAGEM CONTEXTUAL}

Em um arquivo de natureza pessoal tudo é meticulosamente arquitetado? Não há o que escape aos desígnios do titular ou de terceiros envolvidos em seu arquivo? O que se guarda e a razão de sua preservação são sempre objetos de um projeto mais amplo? Lacunas, silêncios, omissões e manipulações fragilizariam o arquivo pessoal? A subjetividade, as interferências externas e a dificuldade em mapear a trajetória do arquivo retiram dele seu caráter arquivístico? A problematização dos conceitos tradicionais da área quando pensados nos arquivos pessoais invalidaria a sua 
compreensão enquanto arquivos e, consequentemente, seu tratamento segundo o prisma da Arquivologia, justificando a adoção de outras metodologias?

Apesar de reconhecerem que os referidos conjuntos documentais apresentam uma série de particularidades e representam um desafio teórico-metodológico para a Arquivologia, alguns autores identificam nestes documentos atributos essenciais (como o valor probatório e a organicidade) que os situam na condição de arquivos e defendem seu tratamento segundo a metodologia arquivística. Ancoram-se, para tal, justamente na característica que define e diferencia o documento de arquivo, qual seja, a sua função de prova. Como a abordagem arquivística se concentra na proteção dessa função, é ela, de acordo com a perspectiva desses autores, que deve ser empregada no tratamento dos arquivos pessoais. Nesse sentido, a contextualização, enquanto procedimento metodológico característico da Arquivologia ganha um papel primordial.

De acordo com Lopez (2003), as informações contidas no documento de arquivo só ganham inteligibilidade quando referidas dentro de seu contexto de produção. Assim, o exame do conteúdo dos documentos ocupa uma posição secundária, visto que a crítica da veracidade documental é desprovida de sentido quando não se pode determinar a autenticidade do documento; é necessário antes deslindar as circunstâncias sob as quais são produzidos os registros, posto que reveladoras do contexto de produção. Quando este contexto deixa de ser a diretriz da organização documental, os processos e funções que geraram os documentos tendem a ser ignorados. Dessa maneira, as propostas de organização de acervos baseadas em outros princípios que não o da proveniência - assunto, especificidade do suporte ou interesse do consulente, por exemplo lidam não com o documento em si, mas com a informação que ele carrega; portanto, não devem constituir critério de organização arquivística. Lopez (2003), desse modo, defende a preponderância do valor probatório sobre o informativo, isto é, do valor externo sobre o interno.

Por seu turno, Camargo (2009) afirma que a condição sine qua non para definir o documento de arquivo é a natureza probatória, a qual incide exclusivamente sobre a atividade que produziu o registro. Ainda que outros empregos e valores possam ser atribuídos ao documento posteriormente, aquela função probatória que lhe deu origem não se perde nem se invalida e é na preservação dela que se concentra o fazer arquivístico. Por este 
motivo, o vasto leque de elucubrações possíveis praticadas pelas disciplinas que se lançam sobre os arquivos pessoais não inviabilizaria a abordagem apregoada pela teoria arquivística.

Rebatendo as afirmações de que os arquivos pessoais são construções cujos artífices são a instituição, os arquivistas e os responsáveis pela acumulação, que os documentos participariam da fabricação de um relato e que o arquivo seria uma figura epistemológica desenhada a partir de determinadas práticas discursivas, Camargo (2009) sustenta que os arquivos estão imunes às possibilidades de exploração. De acordo com a autora, supor que todo arquivo, em virtude de sua natureza pessoal, possui uma dimensão autobiográfica, sendo conscientemente produzido e marcado por distorções, significa ignorar a condição de prova oriunda das atividades ménagères. $\mathrm{E}$ o contrário também se verifica, pois caso o arquivo pessoal fosse atividade finalística, empenhada na edificação de uma dada imagem, ele deixaria de ser arquivo. (CAMARGO, 2009, p. 36).

Ao alegar que é a função originária que garante ao documento a longevidade e a potencialidade que lhe permitem ser material para múltiplos usos e interpretações, a autora reforça o papel dos arquivistas em identificar e representar o contexto documental, garantindo, assim, o caráter probatório e a autenticidade do registro. Segundo Camargo (2009), não obstante a informalidade que caracteriza muitos documentos de arquivo pessoal, o arquivista deve investir seus esforços na preservação do sentido originário, ou seja, do nexo entre o documento e a atividade por ele viabilizada ou comprovada.

Com efeito, a perspectiva da autora pode ser vislumbrada na metodologia aplicada durante os trabalhos de organização dos documentos custodiados pela Fundação Fernando Henrique Cardoso (FFHC). Tomando como ponto de partida a necessidade de abordar o arquivo pessoal como um todo orgânico e indissociável, a sugestão de tratamento proposto por Camargo e Goulart (2007) teve como finalidade, de forma compatibilizada, preservar a organicidade do conjunto, tornar operacionais as atividades de arranjo e descrição e proporcionar o acesso aos documentos.

De modo não convencional, Camargo e Goulart (2007) optaram por aplicar, de forma individualizada, práticas descritivas comuns a documentos de arquivo, livros e objetos tridimensionais, não ignorando, contudo, as particularidades de cada um, bem como as convenções empregadas em suas respectivas áreas. De acordo com a metodologia proposta, a classificação desses diversos itens 
incide sobre as unidades de descrição, que, independente de conteúdo, suporte, forma ou formato, equivalem, preferencialmente, ao documento singular, cuja individualidade busca-se recuperar através de seu contexto de acumulação. A capacidade de evocar ou representar as circunstâncias que motivaram a acumulação e guarda dos itens é, dessa forma, preservada.

Assentada no método funcional, a experiência de Camargo e Goulart (2007) no tratamento dos arquivos pessoais custodiados pela Fundação FHC priorizou a identificação das funções e atividades do titular do fundo, objetivando a contextualização da produção documental e a preservação da organicidade. Segundo essa metodologia, cada fundo goza de uma identidade própria e, por conseguinte, sua organização deve espelhar a singularidade das funções desenvolvidas por seu titular ao longo da vida. Essa é uma proposta de organização que exige um árduo e longo trabalho de pesquisa por parte do arquivista, o qual deve empenhar-se na recuperação do contexto de produção do documento a fim de proteger a função que lhe deu origem (e consequentemente sua capacidade de prová-la), bem como sua relação com os outros registros do conjunto.

\section{CONSIDERAÇÕES FINAIS}

Os arquivos pessoais vêm ganhando destaque nas discussões e na literatura arquivística brasileira nas últimas décadas. Verifica-se um aumento das pesquisas e da produção científica sobre o tema no país, assim como um crescimento da realização de encontros acadêmicos dedicados exclusivamente aos arquivos pessoais, sobretudo por instituições custodiadoras desses arquivos.

Seja como instrumento ou como objeto de estudo em si, os documentos acumulados por um indivíduo ao longo de sua trajetória de vida, em virtude de seu grande potencial informacional, atraem a atenção de estudiosos não apenas da Arquivologia, mas de diversas áreas do conhecimento. Essa valorização manifesta-se na chamada Lei de Arquivos (Lei 8.159/91), que inclui os conjuntos de documentos produzidos e recebidos por pessoas físicas na definição de arquivo expressa em seu segundo artigo, assegurando, assim, o estatuto arquivístico a tais conjuntos.

Todavia, o reconhecimento do estatuto arquivístico não é consensual entre os estudiosos que se debruçam sobre esses conjuntos documentais. Vislumbram-se, então, distintas perspectivas. Alguns autores entendem esses conjuntos como uma construção, 
produto de intenções e manipulações várias e de vários, negando-lhes atributos e princípios da teoria arquivística. Outros, por sua vez, os compreendem como arquivo de forma plena, defendendo seu tratamento segundo a abordagem contextual e sinalizando para os riscos do não reconhecimento de seu caráter arquivístico.

Com efeito, as ideias dos autores adeptos da abordagem contextual reforçam o entendimento dos arquivos pessoais enquanto arquivos e, em certa medida, buscam responder aos questionamentos e dúvidas que os fragilizam. Conforme essa perspectiva, os documentos produzidos e/ou acumulados no decorrer das funções e atividades - independentemente de sua natureza - empreendidas por um indivíduo possuem valor de prova de boa parte dessas funções e atividades, residindo aí a característica fundamental que os identifica como documentos de arquivo, o que justifica seu tratamento de acordo com a metodologia arquivística.

Para Delmas:

Todos os arquivos são resultado da ação humana do indivíduo ou do organismo que os produz, recebe e reúne ao longo de uma atividade, e tais documentos se revestem de caráter pessoal. Dizem respeito à 'vida privada' de alguém ou de um organismo, embora possam interessar indiretamente a várias outras pessoas, com as quais mantêm ligação mais ou menos importante. (DELMAS, 2010, p. 56-59).

Por fim, conforme sublinhou Delmas (2010), a definição de arquivo deve, necessariamente, englobar os conjuntos documentais produzidos e acumulados por pessoas físicas no transcurso de suas atividades, uma vez que, em que pese certos olhares divergentes ainda hoje presentes nos estudos empreendidos na área, os arquivos pessoais são dotados de organicidade à semelhança dos arquivos institucionais.

\section{REFERÊNCIAS}

ABREU, Jorge Phelipe Lira. Arquivos pessoais e teoria arquivística: considerações a partir da trajetória do conceito de arquivo. In: CAMPOS, José Francisco Guelfi (Org). Arquivos privados: abordagens plurais. São Paulo: Associação de arquivistas de São Paulo, 2016.

ARTIĖRES, Philippe. Arquivar a própria vida. Revista Estudos Históricos, 21. Rio de Janeiro: FGV/CPDOC, 1998.

Arquivar-se: a propósito de certas práticas de autoarquivamento. In: TRAVANCAS, Isabel; ROUCHOU, Joëlle; HEYMANN, Luciana. (Orgs.). 
Arquivos Pessoais: reflexões multidisciplinares e experiências de pesquisa. Rio de Janeiro: Editora FGV, 2013.

BELLOTTO, Heloísa L. Arquivos pessoais em face da teoria arquivística tradicional: debate com Terry Cook. Revista Estudos Históricos, 21. Rio de Janeiro: FGV/CPDOC, 1998.

Arquivos pessoais como fonte de pesquisa. In: Arquivos permanentes: tratamento documental. Rio de Janeiro: Editora FGV, 2006.

BRASIL. Lei $n^{\circ} 8.159$, de 8 de janeiro de 1991. Dispõe sobre a política nacional de arquivos públicos e privados e dá outras providências. Brasil, Disponivel em: http://www.planalto.gov.br/CCIVIL_03/LEIS/L8159.htm. Acesso em: 15 fev. 2019.

Decreto $n^{\circ} 4.073$, de 3 de janeiro de 2002. Regulamenta a Lei no 8.159, de 8 de janeiro de 1991, que dispõe sobre a política nacional de arquivos públicos e privados. Brasil, Disponível em: http://www.planalto. gov.br/ccivil_03/decreto/2002/D4073.htm. Acesso em: 9 fev. 2019.

CALLEJA, Mireya. ¿Archivos privados o colecciones?: fuentes primarias para la investigación de la identidade. In: Congreso de Archivología del Mercosur, n. 7, 2007, Viña del Mar.

CAMARGO, Ana Maria de Almeida; GOULART, Silvana. Tempo e circunstância: a abordagem contextual dos arquivos pessoais. São Paulo: Instituto Fernando Henrique Cardoso, 2007.

CAMARGO, Ana Maria de Almeida. Arquivos Pessoais são Arquivos. Revista do Arquivo Público Mineiro, Belo Horizonte, n. 2, p. 26-39, jul-dez. 2009.

. Contribuições para uma abordagem diplomática dos arquivos pessoais.

Revista Estudos Históricos, 21. Rio de Janeiro: FGV/CPDOC, 1998.

Sobre espécies e tipos documentais. In: ARDAILLON, Danielle (Org.). Dar nome aos documentos: da teoria à prática. São Paulo: Fundação FHC, 2013. p. 14-30.

Síntese dos principais temas e discussões. In: ARDAILLON, $\overline{\text { Danielle }}$ (Org.). Dar nome aos documentos: da teoria à prática. São Paulo: Fundação FHC, 2013. p. 286-294.

COOK, Terry. A ciência arquivística e o pós-modernismo: novas formulações para conceitos antigos. In: CID: R. Ci. Inf. e Doc., Ribeirão Preto, v. 3, n. 2, p. 3-27, jul./dez. 2012.

DELMAS, Bruno. Arquivos para quê? São Paulo: Instituto FHC, 2010.

DURANTI, Luciana. Registros documentais contemporâneos como provas de ação. Revista Estudos Históricos, Rio de Janeiro, v. 7, n. 13, p. 49-64, jul. 1994.

HEYMANN, Luciana Quillet. Indivíduo, memória e resíduo histórico: uma reflexão sobre arquivos pessoais e o caso Filinto Muller. Revista Estudos Históricos, 21. Rio de Janeiro: FGV/CPDOC, 1997. 
O lugar do arquivo: a construção do legado de Darcy Ribeiro. Rio de Janeiro: Faperj, 2012.

HOBBS, Catherine. Vislumbrando o pessoal: reconstruindo traços da vida pessoal. In: EASTWOOD, Terry; MACNEIL, Heather. (Org.). Correntes atuais do pensamento arquivístico. Belo Horizonte: UFMG, 2016, p. 47-74.

LISSOVSKY, Maurício; SÁ, Paulo Sérgio Moraes de; VIANNA, Aurélio. A vontade de guardar: lógica de acumulação em arquivos privados. Arquivo \& Administração. Rio de Janeiro, 10-14 (2). 62-76, jul/dez, 1986.

LOPEZ, André Porto Ancona. Documento e história. In: MALEBRA, Jurandir. (Org.). A velha história: teoria, método e historiografia. Campinas (SP): Papirus, 1996, p. 69-87.

. Arquivos pessoais e as fronteiras da Arquivologia. Gragoatá, Niterói, n. 15, p. 69-82, 2003.

McKEMMISH, Sue. Provas de mim... Novas considerações. In: Arquivos Pessoais: reflexões multidisciplinares e experiências de pesquisa. Rio de Janeiro: Editora FGV, 2013.

OLIVEIRA, Lucia Maria Velloso de. Descrição e pesquisa: reflexões em torno dos arquivos pessoais. Rio de Janeiro: Móbile, 2012.

SANTOS, Paulo Roberto Elian dos. Arquivos de cientistas: gênese documental e procedimentos de organização. Associação de Arquivistas de São Paulo. São Paulo: ARQ-SP, 2012. 